style, en utilisant sans cesse la connaissance précise qu'il a de ce monde, en valorisant des opérations essentielles telles que le démontage, l'entretien ou le réglage. Enfin, Laurence Rosier étudie l'ethos sur Facebook dans sa contribution. D'entrée, l'auteure pose qu'elle est tout à fait consciente de présenter un corpus biaisé par le filtre qui est son propre profil Facebook et la communauté discursive réduite à « ses amis". A la question de savoir comment se construisent les ethos sur Facebook, Rosier soutient que les dimensions " narcissique " et métadiscursive vont s'articuler " pour développer selon les communautés sociologiques particulières, un ethos interactif : l'ethos préalable va s'approfondir,

Bauvarie Mounga [bauvarie2004@yahoo.fr]

Université de Yaoundé I, Cameroun

DOI 10.5817/ERB2016-2-20 s'infléchir, voire se modifier en vertu de l'attente du groupe.» (p. 228)

Cet ouvrage apporte un éclairage de plus sur la notion de style. Toutefois, il a la particularité d'insister sur l'ethos des auteurs qui se construit et se forme tout au long de leurs textes. Il permet donc de comprendre comment chaque homme, chaque auteur façonne son style dans le but de séduire les lecteurs. C'est un ouvrage qui, à travers un style simple et efficace, donne les clés au lecteur pour mieux cerner la notion d'ethos et partant la notion de style, afin de mieux analyser les auteurs. Cet ouvrage est utile pour tous les étudiants et chercheurs en stylistique.

\title{
Anthony Mangeon
}

\section{Crimes d'auteur. De l'influence, du plagiat et de l'assassinat en littérature}

Paris, Editions Hermann 2016, 202p.

Dans cet ouvrage, Anthony Mangeon examine les liens entre plagiat et meurtre d'un écrivain par un autre. Dans cette optique, il est question d'étudier les crimes d'auteur dans des récits qui mettent en scène la figure de l'écrivain ou la production d'une œuvre littéraire. Pour mener à bien son analyse, l'auteur subdivise son ouvrage en sept chapitres.

Dans le premier chapitre, Mangeon s'intéresse aux exécutions littéraires. Il s'agit des œuvres dont l'intrigue porte sur des essais ou des désirs de plagiat et des actes meurtriers commis par un aspirant écrivain. L'auteur prend l'exemple de plusieurs œuvres parmi lesquelles le premier roman de Louis Aragon intitulé Anicet ou le panorama, roman (1920). Ce roman parle d'un jeune poète, Anicet, qui désire se faire un nom dans le monde littéraire et chassé de la demeure familiale par ses parents. Aragon invente plusieurs personnages qui représentent des écrivains. On peut citer par exemple Ange Miracle qui incarne jean Cocteau, Baptiste Ajamais représente André Breton, Jean Chipre est Max Jacob. Anicet s'engage dans une aventure iconoclaste qui consiste à détruire une à une les idoles esthétiques littéraires et sociales des écoles artistiques ou des classes dominantes. En outre, le jeune homme va tuer son rival amoureux. A travers l'analyse des exécutions littéraires dans quelques œuvres, on se rend compte que la littérature est un champ social où l'on rencontre également des désirs, des rivalités. Mangeon soutient que «les écrivains, aussi brillants fussentils, ne sont pas exempts de petites bassesses, d'obscures tentations, de secrètes pulsion criminelles ou de grandioses crises de violence. » (p. 41)

Le deuxième chapitre est réservé à l'analyse de quelques romans et nouvelles qui mettent en exergue des écrivains spoliés. Mangeon interroge les liens réels ou fictifs que ces récits entretiennent entre eux ou avec d'autres textes. C'est le cas du premier récit de Sembène Ousmane, Le Docker noir (1956). Ce roman retrace la vie d'un jeune Sénégalais Diaw Falla, docker à Marseille, qui s'essaye à la fiction et va finir par écrire un roman qu'il remet à une écrivaine blanche pour l'aider à le faire éditer. Malheureusement, cette dernière va plutôt éditer le 
roman sous son nom et Diaw finira par la tuer involontairement dans un mouvement de colère. A en croire Mangeon, « avec son « histoire d'un écrivain noir [...] qui se fait ravir son roman par une écrivaine blanche ", Sembène soulève donc un certain nombre d'enjeux essentiels dans les rapports entre France et Afrique, ou entre littérature française et littérature francophone. » (p. 46) Par ailleurs, Sembène Ousmane sera lui-même accusé de plagiat sur d'autres écrivains. C'est dans cette perspective que Bernard Mouralis y voit une réécriture de Tamango de Prosper Mérimée.

Crimes et plagiats parodiques est le titre du troisième chapitre. Il s'intéresse aux récits qui ont une dimension parodique. Le but est de montrer comment ces fictions proposent une réflexion soutenue sur la rivalité mimétique comme moteur de la création littéraire. Mangeon prend l'exemple d'Alain Mabanckou qui s'inspire beaucoup des auteurs afro-américains. Et de ce fait, il subvertit leur stratégie littéraire et politique en prônant un désengagement de l'écrivain noir, au profit de sa plus grande intégration dans le marché littéraire global. Son roman African psycho, paru en 2003, se présente comme une africanisation d'American psycho (2001) de l'Américain Bret Easton Ellis. C'est le journal d'un loser qui a pour idole un grand meurtrier, cependant il ne parvient même pas à exécuter les piètres crimes qu'il ambitionne. Appartenant en apparence au registre policier et parodique qui se cantonne dans le pur divertissement, « le roman de Mabanckou nous parle surtout de littérature. Ce serait plutôt l'histoire d'un apprenti-auteur essayant par mimétisme de dépasser son modèle précieux qui nous serait donné à lire. » (p. 78)

Mangeon analyse, dans le quatrième chapitre, la filiation qui lie Henri Lopes à Louis Aragon. De fait, lécrivain congolais n'a cessé de rendre hommage au poète et romancier français. On peut mentionner ainsi le titre de son œuvre La Nouvelle romance (1976) tiré de l'incipit des Cloches de Bâle. Un autre de ses romans, Le Pleurer-rire (1982) fait tout simplement écho au roman Le Mentir-vrai par le truchement de Beaumarchais, référence commune à Lopes et Aragon. Selon Anthony Mangeon, par ces effets de miroir et de mise en abyme, Lopes présente un portrait de lui-même aussi dévastateur qu'ironique, en même temps qu'il révèle certains des ressorts essentiels de la vie littéraire.

Les problématiques suivantes sont explorées dans le cinquième chapitre : porosité de l'imaginaire et du vécu, mentir-vrai et puissance de la fiction, pastiche et auto parodie, dédoublements et crimes d'auteur. Mangeon prend l'exemple de Romain Gary notamment avec son œuvre La Vie devant soi (1975). En effet, Romain Gary a écrit ce roman sous le pseudonyme d'Emile Ajar. Le roman rencontre un franc succès couronné par l'obtention du prix Goncourt. Sous la pression des médias, Gary demande à son neveu Paul Pavlowitch de se présenter comme auteur. Cependant, ce dernier dépasse les limites, ce qui va pousser Romain Gary à vouloir rétablir la vérité. Il rédige alors un nouveau roman avec comme pseudo le nom de Paul Pavlowitch et narré à la première personne. Toute l'intrigue tourne autour de la question de l'engendrement et de la paternité littéraire ou biologique.

Anthony Mangeons scrute dans le sixième chapitre le « roman de campus » qui analyse les relations complexes entre trois institutions de la république des lettres : l'université, l'industrie du livre et la distribution des prix. Les romans dits de campus, par leurs mises en abyme de la vie littéraire et universitaire, entretiennent d'importantes relations avec d'autres œuvres, tout en autorisant de féconds rapprochements entre eux. Mourir à Francfort d'Hubert Monteilhet (1975) et Effacement de Percival Everett (2001) parus à vingt-cinq ans de distance présentent néanmoins de nombreuses similitudes.

Dans le sixième chapitre, Mangeon se consacre aux effets de miroir entre écrit et écran à l'intérieur de certaines œuvres et de leurs adaptations cinématographiques, afin de montrer notamment comment elles mettent en abyme la réécriture comme une nouvelle création, tout en se jouant, avec diverses variations, d'un programme restreint d'éléments narratifs : la rivalité littéraire, la rivalité amoureuse, l'équivalence ou la consécution entre plagiat et meurtre.

Louvrage d'Anthony Mangeon est intéressant dans la mesure où il permet au lecteur de s'interroger sur les ressorts de la création littéraire, ses 
mobiles, ses motifs, ses enjeux. De plus, l'auteur procède par une organisation rigoureuse et appuie son raisonnement sur une bibliographie fouillée.
Cet ouvrage s'adresse aux étudiants et chercheurs en littérature, en littérature comparée, en intertextualité et polyphonie.

BAUVARIE Mounga [bauvarie2004@yahoo.fr]

Université de Yaoundé I, Cameroun

DOI 10.5817/ERB2016-2-21

\title{
Antonio Pamies Bertrán, Miroslav Valeš
}

\section{El subjuntivo español y su equivalencia en checo}

\author{
Granada, Granada Lingvistica 2015, 140 p.
}

La lingüística comparada y la lingüística aplicada tienen muchas inquietudes científicas en común dentro de sus respectivas áreas de interés y las van resolviendo cada una dentro de sus específicos marcos teórico-metodológicos. Una de ellas es cómo analizar y, a continuación, explicar al público, tanto general como especializado, fenómenos lingüísticos que las lenguas estudiadas en paralelo no comparten y que pueden causar problemas a la hora de aprender una de dichas lenguas, en labores de traducción, en análisis lingüístico, etc. Son fenómenos que a veces a los hablantes, como explican los autores del presente volumen, debido al filtro de su lengua materna, les parecen innecesarios y arbitrarios (9). En el caso de este volumen, se estudia la problemática del subjuntivo español y su equivalencia en checo; otro posible problema de semejante índole para hablantes del checo podrían ser los determinantes o los verbos ser y estar. Para los estudiantes hispanohablantes el checo les paralizará durante un buen rato con su sistema de declinación, el valor fonológico de la cantidad vocálica, las maneras de expresar el aspecto verbal o los matices de significado que aportan los prefijos que se unen a los verbos.

El objetivo del libro que se comentará a continuación es la problemática del subjuntivo español y las maneras de cómo transferir sus valores al checo. No es la primera vez que se estudia el valor y la equivalencia de este modo verbal español en checo; los autores mismos advierten que el presente estudio cuenta con un antecedente enfocado des- de un punto de vista más bien didáctico (Pamies, Valeš 2010). No obstante, esta vez los autores han decidido profundizar en el análisis del asunto y lo han abordado también desde el lado de la lingüística comparada. Es decir, sin descuidar el potencial didáctico del contenido del volumen y de las cuestiones de aprendizaje del subjuntivo que se tratan en sus páginas, los autores se han aproximado esta vez a la temática desde el punto de vista filológico aplicando a cuestiones de E/LE el aparato metodológico de la lingüística comparada y aportando no solamente un listado de equivalentes de casos del subjuntivo español al checo, sino también posibles explicaciones del por qué de dichas soluciones desde el punto de vista tipológico, es decir, de cómo las dos lenguas en cuestión, el español y el checo, expresan la categoría del modo verbal.

En el primer capítulo, titulado "Los modos en la descripción del español y del checo", Pamies y Valeš ofrecen un buen resumen, relativamente corto pero bien denso y adecuadamente ejemplificado, de cómo ha surgido la categoría de modo en ambas lenguas y de cómo se suele expresar en ellas. Asimismo, analizan concisamente las aproximaciones teórico-metodológicas que explican la categoría en ambas tradiciones gramaticográficas: la hispana (y la románica o la romanística) y la checa (o eslavística). Es de mucho interés y muy pertinente que no se haya omitido cómo se ha ido explicando el subjuntivo en gramáticas y manuales del español para checohablantes, ya que las reflexiones y explicaciones propuestas por sus predecesores 